\title{
Desirable leaf traits for hydrological reinforcement of soil
}

\author{
D. Boldrin ${ }^{1,2}$, A. K. Leung ${ }^{1}$ and A. G. Bengough ${ }^{1,2}$ \\ ${ }^{1}$ School of Science and Engineering, University of Dundee, Dundee, UK \\ ${ }^{2}$ The James Hutton Institution, Invergowrie, Dundee, UK
}

\begin{abstract}
Vegetation has an important influence on slope hydrology and hence slope stability via plant transpiration. Little is known about the relative merit of evergreen versus deciduous shrubs in maintaining suctions through the year. This study aims to quantify the soil-plant-water relations of two shrub species and to identify relevant plant traits that correlate with hydro-mechanical properties of vegetated soil. Corylus avellana L. (Hazel) and Ilex aquifolium L. (Holly) were chosen as contrasting deciduous and evergreen broadleaf species. For each species, three replicates were planted in separated pots of sandy loam soil. Each pot was irrigated until the soil was saturated and then was left to transpire for 20 days. Soil suction, leaf conductance to water vapour $\left(g_{\mathrm{L}}\right)$ and soil penetration resistance were recorded. After testing, some key plant traits were determined. It was found that Hazel dried soil faster than Holly. The mean suction induced by Hazel $(82.9 \pm 1.5 \mathrm{kPa})$ was 2.7 times greater than that induced by Holly $(30.6 \pm 8.2 \mathrm{kPa})$, as Hazel has significantly higher $\mathrm{g}_{\mathrm{L}}$ and specific leaf area. Both suction and soil penetration resistance were strongly correlated with the total leaf area, but not the total leaf biomass.
\end{abstract}

\section{Introduction}

\subsection{Hydrological reinforcement}

Vegetation influences natural and engineered slopes due to root growth and root-water uptake driven by plant transpiration $[1,2,3]$. The associated change in the matric suction of soil will affect the stability of these slopes. Pollen-Bankhead and Simon [2] showed that changes in matric suction due to tree transpiration provided the greatest potential benefit to the streambank stability during the growing season. The study also showed that while mechanical root reinforcement increased the streambank factor of safety $(F s)$ by $25 \%$, the effect of transpiration on matric suction translated in a much more significant increase in $F_{S}$ by $52 \%$ during growing season. Pollen-Bankhead and Simon [2] introduced a term, hydrological reinforcement, to describe the increase in soil strength due to plant-induced suction in analogy with the well-recognised mechanical root reinforcement.

A more recent field study conducted by Rahardjo et al. [3] showed that shrub and grass covers preserved significant matric suction in an instrumented slope during rainfall, maintaining the slope stability. While the control fallow slope had $25.9 \%$ drop in Fs after $24 \mathrm{~h}$ of rainfall, the slopes covered with the shrub and the grass had a decrease of only 5.9 and $6.2 \%$ in $F s$, respectively.

\subsection{Plant water relations}

It is apparent that plants can help stabilise slopes hydrologically, but there is limited knowledge of hydromechanical properties of vegetated soil, such as soil strength enhancement due to the increase in transpirationinduced suction, and their correlation with plant functional traits. There is thus a need to better integrate the knowledge from environmental plant physiology with unsaturated soil mechanics.

Water transport from the soil, through the plant, to the atmosphere, takes place in a soil-plant-air continuum (SPAC) that is interconnected by a continuous film of liquid water maintained in tension by a water potential gradient [4]. Leaves and, in particular, stomata largely control plant water relations because of the steep gradient of water potential between leaf and air [5]. Stomatal conductance depends on various plant and environmental factors, including species, plant water status and relative humidity [6]. Leaf conductance to water vapor $\left(\mathrm{g}_{\mathrm{L}}\right)$ limits transpiration rate and reflects the regulatory control exerted by the stomata as well as mesophyll and cuticle conductance. $\mathrm{gL}$ can be expressed as the ratio of the rate of transpiration to the driving force for evaporation, which is the pressure gradient in water vapor from the intercellular spaces in the leaf to the atmosphere. Maximum $\mathrm{g}_{\mathrm{L}}$ varies among plant functional groups with minimum and maximum values recorded in succulents and in plant of wet habitats, respectively [5]. Changes in stomatal opening and $\mathrm{g}_{\mathrm{L}}$ can strongly affect soil water depletion by plants and hence the magnitude of suction developed in

\footnotetext{
$\overline{{ }^{a} \text { Corresponding author:aleung@dundee.ac.uk }}$
} 
wide vegetated areas. Decrease in transpiration due to the closure of stomata slows the rate of soil water depletion. For example, Hussain et al. [7] show that the decrease in evapotranspiration (ET) by $9 \%$ in Maize's field induced a soil moisture increase by $5 \%-10 \%$.

Deciduous and evergreen phonologies in coldtemperate climate have mainly evolved as response to freezing-induced cavitation and consequent interruption of SPAC [8]. Evergreens, transpiring when frost occurs, have small vessels that are less likely to cavitate, but have limited vessel conductance and hence low transpiration rates. On the contrary, the stress avoidance strategy adopted by deciduous species generally compensates for a shorter growing season by large-diameter vessels with high conductance and hence transpiration. [9].

\subsection{Aim and objectives}

In order to identify suitable species for improved slope stabilization, it is necessary to evaluate and select relevant, well-defined and measurable plant functional traits at the individual level and use them as screening criteria for fair comparison across multiple species [10].

Although soil hydrology has been identified to be one of the major factors that govern slope failure [11], the hydrological effect of vegetation is generally ignored in most of the plant selection processes. The current process mainly considers mechanical root reinforcement based on a limited number of biomechanical traits such as root tensile strength and root architecture [12]. One of the major difficulties in incorporating the hydrological effects in such selection process is attributed to a lack of data that reports any correlation between plant functional traits and hydrological reinforcement of the soil.

This study thus aims to quantify the soil-plant-water relations of contrasting deciduous and evergreen broadleaf shrubs native to Europe. Plant functional traits that can correlate with hydro-mechanical properties of vegetated soil such as soil strength are identified.

\section{Materials and Methods}

\subsection{Plant materials}

In this study, two species, Corylus avellana L. (Hazel) and Ilex aquifolium L. (Holly), were chosen as contrasting deciduous and evergreen broadleaf species that would grow into shrubs or small trees. These species are both common in Europe. Both species were supplied by British Hardwood Tree Nursery, Gainsborough, UK and they presented similar dimensions, but different age, approximately 1 and 2 years old, respectively.

\subsection{Soil and planted pots}

Pots with a volume of $4 \mathrm{~L}$ were packed with soil collected from Bullion field, The James Hutton Institute, Dundee, UK. The soil was a sandy loam comprised of sand $71 \%$, silt $19 \%$, clay $10 \%$, with liquid and plastic limits of $32 \%$ and $23 \%$, respectively [13]. The soil (sieved $<10 \mathrm{~mm}$; water content $0.14-0.16 \mathrm{~g} / \mathrm{g}$ ) was dynamically compacted in four layers to obtain an initial dry density of $1200 \mathrm{~kg}$ $\mathrm{m}^{-3}$. The surface of each layer was abraded to achieve a better contact between each successive layer. After compacting the third layer in each pot, a bare root plant was planted in each pot and finally the fourth layer of soil was added. A total of 20 pots for each species were prepared. After transplanting, the soil surface was covered with wecult ${ }^{\circledR}$ discs to decrease evaporation. All plants were maintained in a glasshouse and abundantly irrigated two times a week for two months to favour plant establishment. Plants were considered established when stable canopy development was observed.

Soil water retention curves (SWRCs) of three cores of sandy loam (55 $\mathrm{mm}$ diameter; $40 \mathrm{~mm}$ height) were measured at the same dry density. Each of them was subjected to suctions ranging from 1 to $1500 \mathrm{kPa}$ using a tension table $(1-50 \mathrm{kPa})$ and a pressure plate $(50-1500$ $\mathrm{kPa}$; ELE International, Hemel Hempstead, UK).

\subsection{Monitoring of plant-induced matric suction}

After plant establishment, three replicates of each species were randomly selected from the 20 pots. A miniature tensiometer (SWT-5, $\Delta \mathrm{T}$ devices, Cambridge, UK) was installed in each pot at $0.1 \mathrm{~m}$ below the soil surface for monitoring any matric suction induced by each replicate under glasshouse conditions (average daily temperature $15-18^{\circ} \mathrm{C}$ and daily relative humidity between $50 \%-$ $80 \%$ ). Initially, each pot was irrigated until the soil was saturated (as indicated by $0 \mathrm{kPa}$ by the tensiometer) and it was then left to transpire for 20 days from May $29^{\text {th }}$ to June $17^{\text {th }} 2015$. In order to measure any water loss due to transpiration, each pot was weighed every two days on a balance with an accuracy of $0.1 \mathrm{~g}$. Immediately after each measurement of water loss, matric suction was recorded using the tensiometer.

\subsection{Soil penetration resistance}

To quantify the hydrological reinforcement to the soil due to transpiration-induced suction, soil penetration resistance tests [14] were carried out in each pot using a portable penetrometer (Basic Force Gauge, Mecmesin, UK; cone diameter: $1.94 \mathrm{~mm}$; cone angle: $30^{\circ}$ ). Maximum soil resistance was determined by penetrating the cone to $30 \mathrm{~mm}$ depth from the soil surface. The cone diameter and penetration depth were chosen according to the dimension of the pot [15]. The measurements were taken at three different points for each replicate after 15 days of transpiration. The major advantage of such testing method is that the hydrological reinforcement due to transpiration-induced suction can be isolated from mechanical reinforcement of roots. The use of penetrometer also offers a relatively quick and less destructive way to determine soil strength using simple pots. Due to the simplicity of the testing method, multiple penetration tests can be carried out using the same pot, hence reducing the variability of test results. Soil penetration resistance has been used as a parameter to 
indicate the mechanical or/and hydrological effect of plants on slope stability by Osman and Barakbah [16].

\subsection{Leaf conductance to water vapor}

To quantify plant transpiration, leaf conductance to water vapor $\left(\mathrm{g}_{\mathrm{L}}\right)$ was measured on at least one mature leaf on 19 plants per species using a portable porometer (AP4, $\Delta \mathrm{T}$ devices, Cambridge, UK). This device is a dynamic diffusion porometer, in which part of the leaf is enclosed at the base of a cup containing a humidity sensor. Dry air is then flushed through the cup until a pre-selected lower level of relative humidity is achieved. The flushing then stops and the transit time required for a small, fixed increase in relative humidity is measured. The time taken for the humidity to increase over the fixed interval is related to $g_{L}$ via a calibration curve. Before measurement, the porometer was calibrated using a perforated plate with known diffusive conductance to water vapor. Measurements were performed on a sunny day (June $5^{\text {th }}$ ) on plants in the absence of water stress, which is ideal to prevent stomatal closure and hence negatively affect $\mathrm{g}_{\mathrm{L}}$ measurements. Note that the soil moisture condition for the measurements of $g_{\mathrm{L}}$ in the 19 pots was equivalent to that in the three suction testing pots after four days of transpiration when small suction was developed.

\subsection{Plant traits}

A number of functional leaf traits, including specific leaf area (SLA), total leaf biomass and total leaf area, were determined to correlate with the hydrological responses of the vegetated soils. SLA is defined as the one-sided area of a fresh leaf divided by its oven-dry mass, expressed in $\mathrm{m}^{2} \mathrm{~kg}^{-1}$ [17]. Ten fully expanded leaves per species were collected at early morning (June $16^{\text {th }}$ ) from five plants. Leaves were then scanned and the area was measured using an open source, image analysis software, ImageJ (NIH, USA). Each leaf sample was placed in an oven at $60{ }^{\circ} \mathrm{C}$ for $72 \mathrm{~h}$ to obtain a constant weight measured using an electronic balance with an accuracy of $0.0001 \mathrm{~g}$. SLA was hence calculated by dividing the leaf area by the corresponding leaf dry weight $\left(\mathrm{m}^{2} \mathrm{~kg}^{-1}\right)$.

After the suction monitoring of each pot for 20 days, total leaf biomass of the three replicates was estimated by multiplying the number of leaves by the mean leaf dry biomass, while the total leaf area was calculated by multiplying the number of leaves with the mean leaf area. These testing methods avoid destructive measurements.

\subsection{Statistical analysis}

Statistical analysis was performed using GenStat $17^{\text {th }}$ Edition (VSN International) and SigmaPlot12.5 (Systat Software Inc). The significance of differences between experimental treatments was assessed by Student's t-test. The significance of correlations established in this study was tested using regression analysis. Results were considered statistically significant at $\mathrm{p}$-value $\leq 0.05$.

\section{Results}

The SWRC of the sandy loam is shown in Fig. 1 (van Genuchten-Mualen regression; $\mathrm{m}=1-1 / \mathrm{n} ; \mathrm{r}^{2}=0.99$ ).

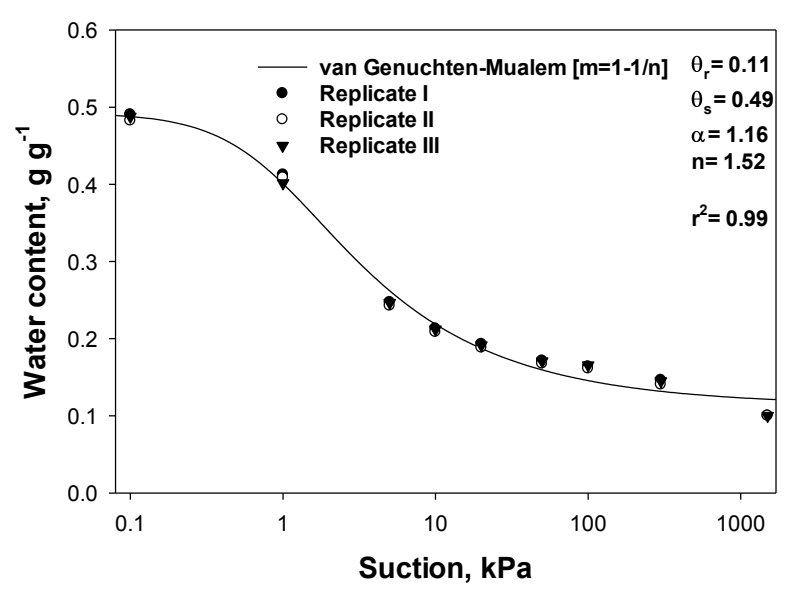

Figure 1. Soil water retention curve of Bullion field soil sieved to $10 \mathrm{~mm}$ and compacted to $1200 \mathrm{~kg} \mathrm{~m}^{-3}$. Van Genuchten model parameters are reported in the graph, as well as $\mathrm{r}^{2}$.

Fig. 2 shows the water loss from planted pots during time from May $28^{\text {th }}$ (soil saturation) to June $17^{\text {th }}$. The difference in water loss between Holly and Hazel pots translated in a large difference in matric suction (Fig. 3). After 20 days of transpiration, the mean suction induced by Hazel $(82.9 \pm 1.5 \mathrm{kPa})$ was 2.7 times greater than that induced by Holly $(30.6 \pm 8.2 \mathrm{kPa})$. The difference of induced suction between Holly and Hazel is found to be statistically significant $(\mathrm{p}$-value $=0.003)$.

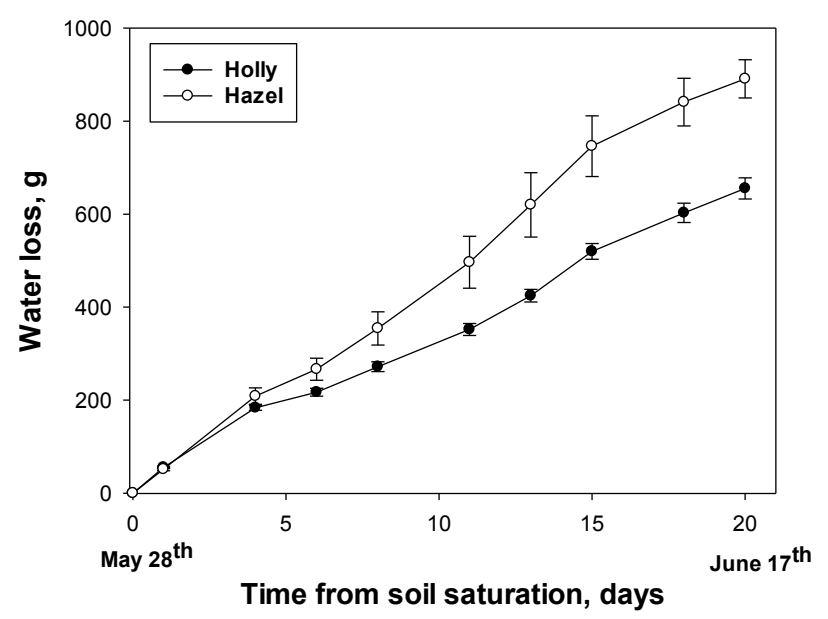

Figure 2. Measured water loss in Holly and Hazel replicate pots during the experimental period, May $28^{\text {th }}-$ June $17^{\text {th }}$. Error bars represent the standard error of mean.

Soil penetration resistance between Holly and Hazel pots is significantly different $(\mathrm{p}$-value $=0.035)$ after 15 days of transpiration, with the minimum value of 1.57 $\mathrm{MPa}$ in Holly pot and maximum value of $9.66 \mathrm{MPa}$ in Hazel pot. Note that these resistances mainly serve as indicators for the relative comparison of the hydrological reinforcement between the two species. A strong correlation $\left(r^{2}=0.93 ; p\right.$-value $\left.=0.001\right)$ between suction 
and soil penetration resistance is sought, highlighting the significance of hydrological reinforcement (Fig. 4).

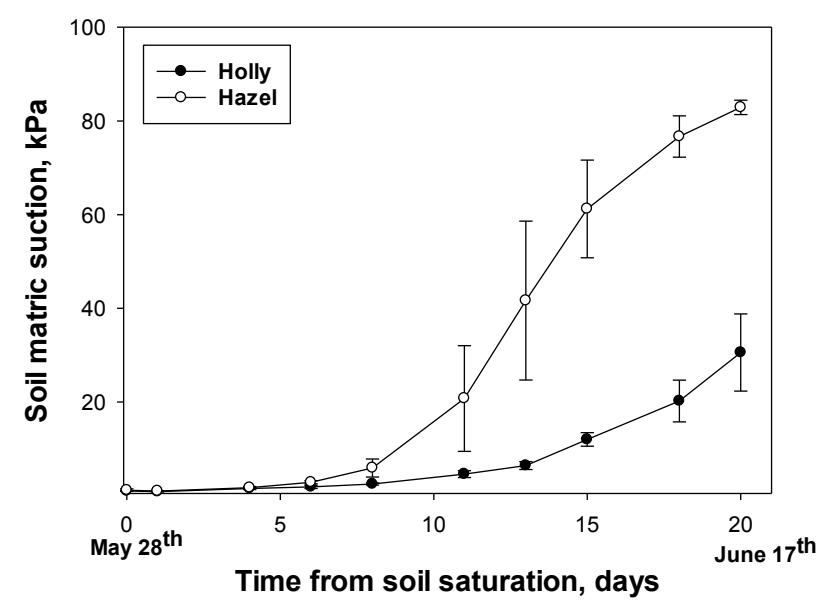

Figure 3. Measured matric suction in Holly and Hazel replicate pots during the experimental period, May $28^{\text {th }}-$ June $17^{\text {th }}$. Error bars represent the standard error of mean.

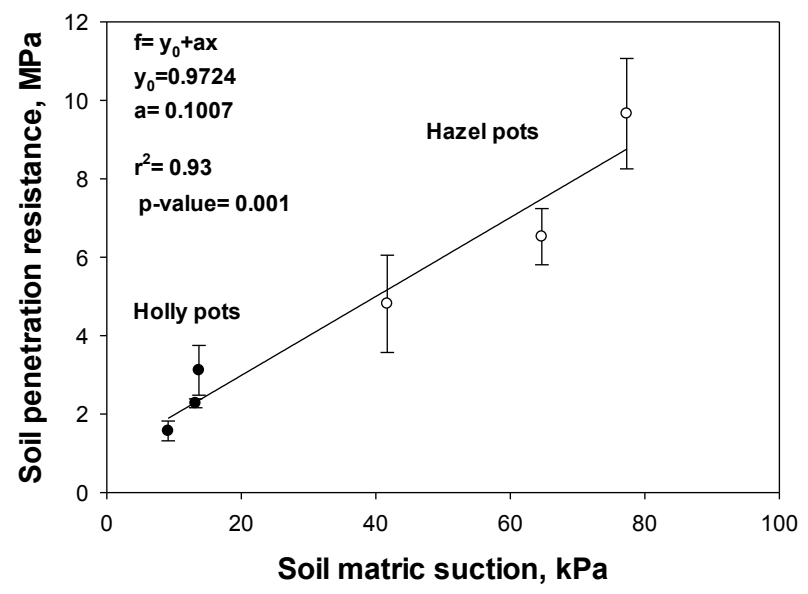

Figure 4. Correlation between matric suction and soil penetration resistance in Hazel and Holly pots, after 15 days of transpiration. Linear regression equation, coefficients $\mathrm{y}_{0}$ and a are reported in the graph, as well as $r^{2}$ and $p$-value. Error bars represent the standard error of mean.

The highly significant difference of SLA between Holly and Hazel (Fig. 5) highlighted their difference in leaf biomass investment and allocation. This is because the mean leaf area of Hazel was 2.2 times higher than that of Holly, whereas the mean leaf mass of Hazel was 1.5 times lower (Table 1).

Table 1. Leaf area and dry mass of Hazel and Holly leaves. Means are reported \pm standard error of mean $(n=10)$.

\begin{tabular}{|l|c|c|}
\hline Species & Leaf area, $\mathbf{~ m m}^{\mathbf{2}}$ & Leaf mass, $\mathbf{g}$ \\
\hline Hazel & $2787.33 \pm 229.02$ & $0.15 \pm 0.02$ \\
\hline Holly & $1260.65 \pm 109.39$ & $0.23 \pm 0.02$ \\
\hline
\end{tabular}

Strong correlations were found between the total leaf area and both matric suction $\left(\mathrm{r}^{2}=0.76\right.$; $\mathrm{p}$-value $=0.01$; Fig. 6A) and soil penetration resistance $\left(r^{2}=0.89 ; p\right.$-value $=0.003$; Fig. $6 \mathrm{~B}$ ). The total leaf area can explain the $76 \%$ of matric suction and $89 \%$ of penetration resistance variability in soil. Although there is no correlation between matric suction and the total leaf biomass when both species are considered (Fig. 7), there is a positive trend between total leaf biomass and matric suction if species are individually considered.

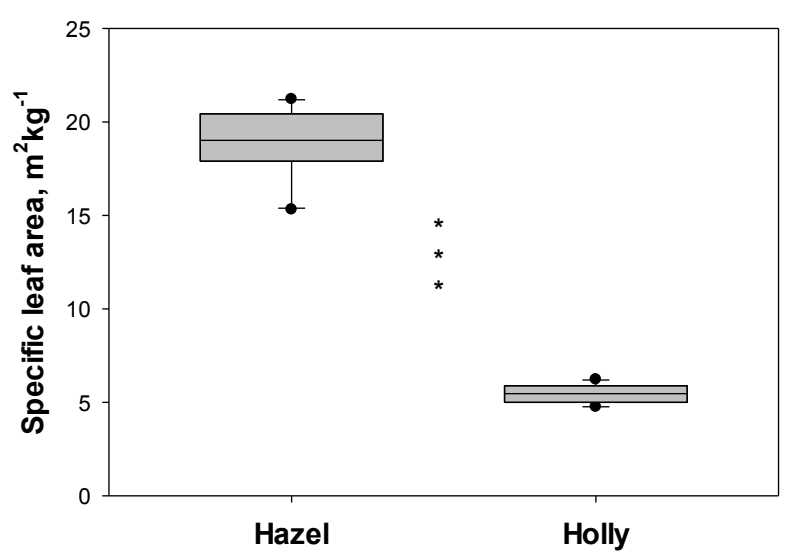

Figure 5. Box plots of Holly's and Hazel's SLA. *** represents a highly significant difference ( $\mathrm{p}$-value $\leq 0.001$; Student's t-test; $\mathrm{n}=10$ ) between the SLA of Holly and Hazel.
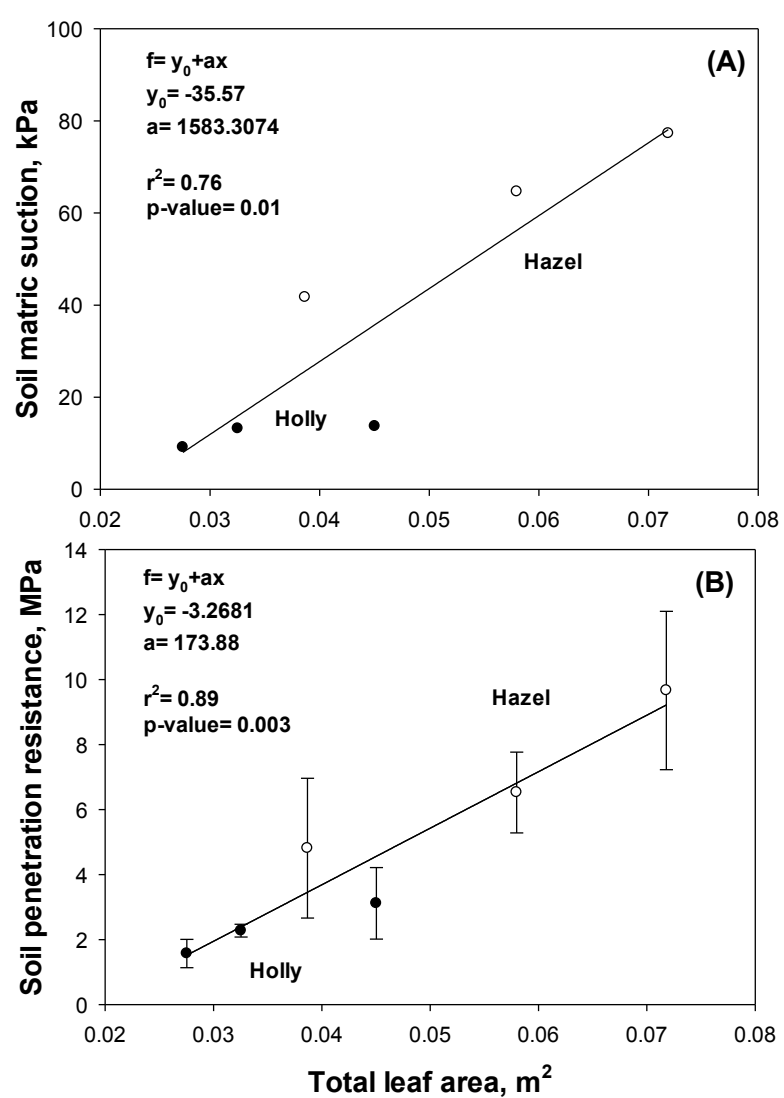

Figure 6. Correlation of total leaf area with (A) matric suction and (B) soil penetration resistance in Hazel and Holly pots, after 15 days of transpiration. Linear regression equation, coefficients $\mathrm{y}_{0}$ and a are reported in the graph, as well as $\mathrm{r}^{2}$ and $\mathrm{p}$-value. Error bars represent standard error of mean. 


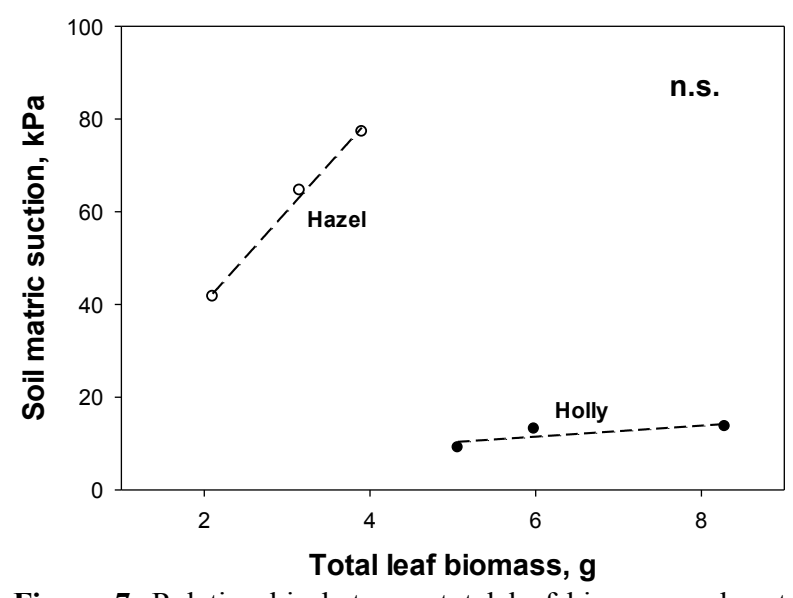

Figure 7. Relationship between total leaf biomass and matric suction in Hazel and Holly pots, after 15 days of transpiration. Dash lines represent positive trends. n.s.: not statistically significant correlation

The leaf conductance to water vapor $\left(\mathrm{g}_{\mathrm{L}}\right)$, recorded in nineteen Holly and Hazel replicates under the same environmental condition, highlights a highly significant difference between the two species (Fig. 8). Hazel has a mean $\mathrm{g}_{\mathrm{L}}\left(84.3 \pm 7.5 \mathrm{mmolm}^{-2} \mathrm{~s}^{-1}\right)$ about 3.2 times higher than Holly $\left(26.1 \pm 3.8\right.$ mmolm $\left.^{-2} \mathrm{~s}^{-1}\right)$.

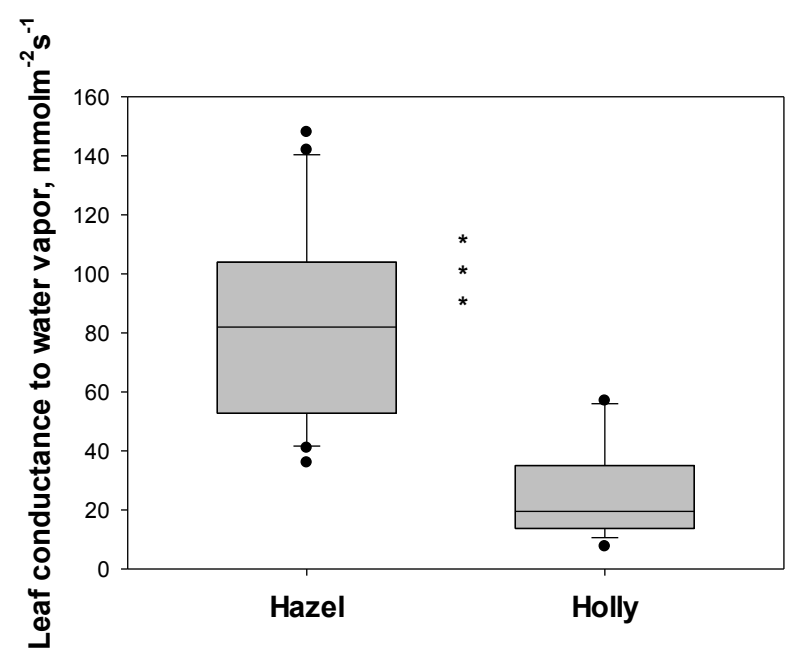

Figure 8. Box plots of the $\mathrm{g}_{\mathrm{L}}$ of Holly and Hazel. *** represents a highly significant difference ( $p$-value $\leq 0.001$; Student's t-test; $\mathrm{n}=19$ ) between the $\mathrm{g}_{\mathrm{L}}$ of Holly and Hazel.

\section{Discussion}

The monitoring of water loss and matric suction (Figs 2 and 3) highlighted that Hazel influenced the soil hydrology more than Holly. The greater hydrological effects of Hazel translated in a three times higher penetration resistance in Hazel pots (Fig. 4).

The regression study shows that total leaf area is an important leaf trait that has strong correlations with plant water uptake capability (i.e. in terms of matric suction; Fig. 6A) and mechanical strength of vegetated soil (i.e. in terms of soil penetration resistance; Fig. 6B). Another important finding is that plant water uptake is not driven by the leaf biomass (Fig. 7), but more by its allocation and investment as leaf area. SLA has been demonstrated to be positively correlated with net photosynthesis [18], potential growth rate [19] and transpiration rate [20]. Differences in SLA between species are the result of different leaf design, which represents the plant investment in leaf tissue [21]. A small SLA, and hence large leaf dry matter per area, translates into more resistant leaves with high leaf life span and hence a slowreturn of initial energy investment in the leaf. On the other hand, large SLA is related to a fast-return of energy investment. In a temperate climate, generally deciduous species, such as Hazel, are characterized by high values of SLA in contrast to evergreens, being the maintenance of canopy leaves during unfavourable seasons a higher investment of nutrients and dry mass than the cost of new leaves [22]. Therefore, species like Hazel maximises the growth and hence the water uptake during the summer growing season, while the evergreen Holly has a slowreturn of energy investment and hence low water use and growth rate. Bochet and García-Fayos [23] identified SLA as an important plant trait associated with the establishment success on road-side slopes in semi-arid environments, reflecting plant competitiveness. Our study highlights the possibility of using SLA as one of the quick and easily-measured screening traits to identify suitable species for hydrological reinforcement of soil.

The higher water uptake of Hazel was also explained by its higher $g_{L}$, as compared with Holly (Fig. 8). As $g_{L}$ is directly proportional to transpiration, this parameter is thus an important driver of plant transpiration to induce suction. Hungate et al. [24] demonstrated that a reduction of $g_{L}$ in scrub-oak woodland can directly reduce the ET of the ecosystem and hence result in relatively wet soil. On natural and engineered slopes, the decrease of ET can cause a decrease in matric suction, and consequently slope stability [25]. Differences in transpiration of Hazel and Holly can be explained by their different phenology: deciduous and evergreen, respectively. While deciduous trees generally compensate for a shorter growing season by producing leaves that have higher photosynthetic rates per unit mass and hence transpiration, evergreen trees are known to have lower hydraulic conductance and an architectural feature that promotes water saving and enhances tolerance during dry and frost periods [9].

As $g_{L}$ is significantly different between Hazel and Holly, this parameter can be a useful indicator of hydrological reinforcement. However, it must be pointed out that $\mathrm{g}_{\mathrm{L}}$ varies with several environmental factors such as water availability, irradiance and relative humidity. We thus suggest the use of $g_{L}$ in plant screening only if plants are under the same environmental conditions and in well water status to avoid stomatal closure.

Although both Hazal and Holly are suggested for their use on road landscapes by the Scottish Government (http://www.gov.scot/Publications), Hazel was shown to be a more efficient species, as far as slope stability is of concern, as this species provides greater hydrological reinforcement due to its high transpiration rate. The high water use of Hazel was also reported in the natural environment by Herbst et al. [26], who found that Hazel determined most of the understory forest ET $(75 \% ; 50$ $\mathrm{mm})$ in a South England forest. Bischetti et al. [27] also 
showed that Hazel roots had the highest tensile strength among different forest species in Italy. Therefore, it seems that Hazel can be a suitable species in terms of hydro-mechanical reinforcement of road-side slopes.

\section{Conclusions}

Our study uses leaf traits to correlate and explain the hydrological reinforcement of vegetated soils due to transpiration-induced suction. Some conclusions may be drawn from this study:

- There are significant differences of hydrological reinforcement to the soil between Hazel and Holly. Hazel induced a mean suction $(82.9 \pm 1.5 \mathrm{kPa})$ that was 2.7 times greater than Holly $(30.6 \pm 8.2 \mathrm{kPa})$, translating to a higher soil penetration resistance.

- Strong correlation between total leaf area and both suction $\left(\mathrm{r}^{2}=0.76\right)$ and soil penetration resistance $\left(\mathrm{r}^{2}=\right.$ 0.89 ) existed, regardless of the species.

- Specific Leaf Area (SLA) may be an indicator of plant water relations as significant differences in SLA were found between Hazal and Holly ( $p$-value $\leq 0.001$ ).

- No correlation was found between total leaf biomass and the matric suction induced by transpiration, when both species are considered.

- Under controlled conditions, $\mathrm{g}_{\mathrm{L}}$ measurements might be a useful parameter for plant screening for hydrological reinforcement associated with plant-induced suction, as the $g_{L}$ of Hazel and Holly were significantly different ( $p$ value $\leq 0.001$ )

The initial results suggest that there is substantial scope to choose species to manipulate hydro-mechanical properties of soil for engineering and ecological functions. Future work is needed to increase the number of species and traits, as well as to quantify seasonal variation in evergreen versus deciduous species in relation to their effects on soil hydrology and resistance.

\section{References}

1 A. Stokes, G. B. Douglas, T. Fourcaud, F. Giadrossich, C. Gillies, and e. al., Plant Soil, 377, 1, 1 (2014).

2 N. Pollen-Bankhead and A. Simon, Geomorphology, 116, 3-4, 353 (2010).

3 H. Rahardjo, A. Satyanaga, E. C. Leong, V. A. Santoso, and Y. S. Ng, Soils and Foundations, 54, 3, 417 (2014).

4 E. Steudle, Annu Rev Plant Phys, 52, 847 (2001).

5 H. Jones, Plants and Microclimate A Quantitative Approach to Environmental Plant Physiology, Cambridge 3ed. (2013).

6 K. Aasamaa and A. Sober, Environ Exp Bot 71, 1, 72 (2011).

7 M. Z. Hussain, A. Vanloocke, M. H. Siebers, U. M. Ruiz-Vera, R. J. C. Markelz, A. D. B. Leakey, D. R. Ort, and C. J. Bernacchi, Glob Change Biol 19, 5, 1572 (2013).

8 H. Lambers, F. S. Chapin, and T. L. Pons, Plant Physiological Ecology, Springer 2 ed. (2008).
9 D. Baldocchi, S. Ma, S. Rambal, L. Misson, J.-M. Ourcival, J.-M. Limousin, J. Pereira, and D. Papale, Ecol appl 20, 6, 1583 (2010).

10 A. Stokes, C. Atger, A. G. Bengough, T. Fourcaud, and R. C. Sidle, Plant Soil, 324 (1-2), 1 (2009).

11 D. G. Toll, S. D. N. Lourenco, J. Mendes, D. Gallipoli, F. D. Evans, and e. al., Q J Eng Geo Hydrog, 44, 1, 23 (2011).

12 S. De Baets, J. Poesen, B. Reubens, K. Wemans, J. De Baerdemaeker, and B. Muys, Plant Soil, 305, 1-2, 207 (2008);

13 K. W. Loades, A. G. Bengough, M. F. Bransby, and P. D. Hallett, Plant Soil, 370, 1-2, 407 (2013).

14 K. Weaich, A. Cass, and K. L. Bristow, Soil Till Res, 25, 2-3, 149 (1992).

15 R. K. Misra and F. D. Li, Soil Till Res, 38, 1-2, 59 (1996).

16 N. Osman and S. S. Barakbah, Ecol Eng, 28, 1, 90 (2006).

17 N. Pérez-Harguindeguy, S. Díaz, E. Garnier, S. Lavorel, H. Poorter, and e. al., Aust J Bot, 61, 3, 167 (2013).

18 P. B. Reich, M. B. Walters, and D. S. Ellsworth, PNAS, = 94, 25, 13730 (1997).

19 J. P. Grime, K. Thompson, R. Hunt, J. G. Hodgson, J. H. C. Cornelissen, I. H. Rorison, and e. al., Oikos, 79, 2, 259 (1997).

20 P. B. Reich, D. S. Ellsworth, M. B. Walters, J. M. Vose, C. Gresham, J. C. Volin, and W. D. Bowman, Ecology, 80, 6, 1955 (1999).

21 I. J. Wright, P. B. Reich, M. Westoby, D. D. Ackerly, Z. Baruch, F. Bongers, and e. al., Nature, 428, 6985, 821 (2004).

22 K. Bai, C. He, X. Wan, and D. Jiang, AoB PLANTS, 7, 1, (2015).

23 E. Bochet and P. García-Fayos, Ecol Eng, 83, 444 (2015).

24 B. A. Hungate, M. Reichstein, P. Dijkstra, D. Johnson, G. Hymus, J. D. Tenhunen, C. R. Hinkle, and B. G. Drake, Glob Change Biol, 8, 3, 289 (2002).

25 J. A. Smethurst, K. M. Briggs, W. Powrie, A. Ridley, and D. J. E. Butcher, Geotechnique, 65, 11, 869 (2015).

26 M. Herbst, P. T. W. Rosier, M. D. Morecroft, and D. J. Gowlng, Tree Physiol, 28, 6, 959 (2008).

27 G. B. Bischetti, E. A. Chiaradia, T. Simonato, B. Speziali, B. Vitali, P. Vullo, and A. Zocco, Plant Soil, 278, 1-2, 11 (2005).

http://www.gov.scot/Publications accessed 14/09/2015 